\title{
EKSISTENSI JANGKOI DALAM KARYA SENI GRAFIS
}

\author{
Repi Justian', Yuniarti Munaf', Dharsono ${ }^{3}$ \\ Program Studi Magister Pascasarjana \\ Institut Seni Indonesia Padangpanjang \\ Jl. Bahder Johan, Guguak Malintang, Padangpanjang, Kota Padangpanjang, 27126. \\ Sumatera Barat. Indonesia \\ Email: justianrepi365@gmail.com,yuniartimunaf1960@gmail.com,eyangdharso2@gmail.com
}

\begin{abstract}
Abstrak
Jangkoi merupakan benda budaya yang masih hidup dan berkembang pada masyarakat Kerinci dari tempo dulu. Jangkoi yaitu alat untuk mengangkut padi saat sudah dituai. Jangkoi pada zaman dahulunya sangat mudah ditemukan di daerah Kerinci, karena benda ini banyak diproduksi para pengrajin, pada umumnya benda ini digunakan penduduk Kerinci yang mata pencaharianya sebagai petani, sehingga dahulunya perkembangan benda budaya ini di tengah-tengah masyarakat Kerinci. Jangkoi saat ini keberadaannya terkesampingkan oleh perkembangan zaman, benda ini dahulunya dekat dengan masyarakat namun sekarang sudah mulai menghilang dan tidak difungsikan lagi karena zaman sudah modren alat-alat tranportasi sangat terjangkau maka dari hal ini lah para petani lebih memakai alat yang lebih efisien dan lebih praktis seperti kendaraan bermotor, gerobak dorong dan lain-lain. Maka dari hal tersebutlah timbul rasa prihatin dan sedih pengkarya bahwa keberadaan benda budaya ini semakin tertinggalkan dan tergilas oleh perkembangan zaman. Metode yang digunakan dalam penciptaan melalui beberapa tahapan sistematis yakni tahap observasi, data lapangan, eksperimen, perenungan dan pembentukan. Dari tahapan tersebut diperoleh bentuk simbol personal. Simbol yang hadir berbagai macam bentuk visualny mengikuti ekspresi perasaan pengkarya terhadap karya itu sendiri. Karya ini digarap menggunakan teknik grafis konvensional yakni cetak tinggi (reliefprint) namun pewarnaannya menggunakan handcolouring, maka pada karya ini ialah mixmedium.
\end{abstract}

Kata Kunci: jangkoi, subjek matter, seni grafis.

\begin{abstract}
Jangkoi is a cultural object that is still alive and well in the Kerinci community from the past. "Jangkoi" is a tool for transporting rice when it is harvested. Jangkoi in the past was very easy to find in the Kerinci area, because these objects were produced by many craftsmen, in general these objects were used by Kerinci residents whose livelihoods were farmers, so that in the past the development of this cultural object was in the midst of the Kerinci community. Jangkoi is currently being sidelined by the times, this object used to be close to the community but now it has begun to disappear and is no longer functional because of the modern times, the means of transportation are very affordable, so from this, farmers use more efficient and more efficient tools. more practical, such as motorized vehicles, wheelbarrows and others. So from this there arises a sense of concern and sorrow for the workers that the existence of these cultural objects is increasingly being abandoned and crushed by the times. The method used in creation goes through several systematic stages, namely the observation, field data, experiment, reflection and formation stages. From this stage, a personal symbol is obtained. The symbols present in various visual forms follow the expression of the writer's feelings towards the work itself. This work was produced using conventional graphic techniques, namely high print (relief print), but the coloring uses hand-coloring, so in this work is mix medium.
\end{abstract}

Keywords: jangkoi, subject matter, graphic arts.

\section{PENDAHULUAN}

Jangkoi merupakan benda budaya yang masih hidup dan berkembang pada masyarakat Kerinci dari tempo dulu. Benda budaya ini dibuat dengan bentuk bulat pada bagian atas, tetapi semakin ke bawah semakin mengecil membentuk persegi. Benda ini terbuat dari bahan rotan yang dibelah-belah dan terjalin sedemikian rupa dengan alat penyangga yang ditempatkan pada empat sudut. Pada bagian bawah benda ini diberi belahan kayu menyilang dari kayu surian sambil menghubungkan ke empat sudut bambu penyangganya. Jangkoi dilengkapi dengan tali di kepala untuk menyandangnya. Benda tersebut digunakan untuk mengangkut padi saat sudah dituai. 
Dilihat dari fungsinya "Jangkoi" digunakan untuk menyimpan, menimbun dan memuat barang hasil tani sehari-hari ${ }^{[1]}$.

Selain digunakan oleh petani, Jangkoi juga dijadikan ciri khas kebudayaan masyarakat Kerinci karena masyarakat kerinci pada umumnya bekerja sebagai petani yang mempunyai lahan pertanian yang luas sehingga benda ini merupakan alat tradisional penampung hasil panen. Keberadaan Jangkoi saat ini mulai menghilang karena para petani lebih memakai alat yang lebih efisien dan praktis seperti kendaraan bermotor, gerobak dorong dan lain-lain.

Jangkoi memiliki peran yang sangat vital terhadap kebutuhan masyarakat Kerinci. Keberadaan Jangkoi saat ini membuat pengkarya peka terhadap eksistensinya yang semakin memprihatinkan semakin minim dipergunakan. Zaman dulu benda budaya ini memiliki peran penting dalam kehidupan masyarakat Kerinci yang sulit terpisahkan dengan mata pencaharian masyarakat saat itu, sehingga timbul rasa prihatin dan sedih pengkarya bahwa keberadaan benda budaya ini semakin tertinggalkan dan tergilas oleh perkembangan zaman. Pengkarya begitu peka terhadap Jangkoi dan ingin mengkaji lebih mendalam lagi tentang bagaimana eksistensinya pada perkembangan zaman sehingga dituangkan dalam karya seni grafis.

Karya seni grafis yang akan dibuat menggunakan konsep Surrealisme. Breton mengatakan bahwa Surrealisme adalah otomatis psikis yang murni, dengan proses pemikiran yang sebenarnya untuk diekspresikan secara verbal, tertulis ataupun cara lain. Surrealisme bersandar pada keyakinan realitas yang superior dari kebebasan asosiasi,keserbabisaan mimpi, pemikiran kita yang otomatis tanpa kontrol dari kesadaran. Kreatifitas kaum Surrealis berusaha membebaskan dari kontrol kesadaran, menghendaki sebebas orang yang sedang bermimpi ${ }^{[2]}$.

Surrelime membuat kebebasan dari karya yang lahir nantinya, kebebasan berekspresi, perasaan personal yang menyentuh kalbu pengkarya menanggapi apa yang terjadi pada benda budaya Jangkoi saat ini. Alasan ketertarikan terhadap "Jangkoi" yang menjadikan penting dan layak untuk diangkat. Sehingga menjadi perhatian bagi pengkarya untuk dituangkan kedalam karya Seni Grafis serta di harapkan semoga karya ini memberi pengetahuan bahwa Jangkoi merupakan salah satu benda budaya yang memiliki peran dan mengambil bagian terpenting dalam kelangsungan hidup masyarakat Kerinci
Gorga : Jurnal Seni Rupa

Volume 09 Nomor 02 Juli-Desember 2020 p-ISSN: 2301-5942 | e-ISSN: 2580-2380

dahulunya dan memperbaharuinya melalui cara lain sebagai bentuk pelestarian, serta memberi wawasan tentang seni dan kesenian serta pengetahuan budaya serta tradisi yang sangat minim

diketahui oleh masyarakat Kerinci khususnya. Sehingga penting untuk diangkat sebagai ide karya Seni Grafis.

\section{KAJIAN TEORI}

\section{Tinjauan Karya}

Penciptaan karya seni rupa khususnya seni rupa murni merupakan sebuah rangkaian serta proses yang panjang, berawal dari kepekaan ruang kalbu pengkarya menanggapi fenomena yang terjadi dilingkungan masyarakat saat ini. Fenomenafenomena yang berada dari luar diri pengkarya menjadi sebuah ide hadirnya karya seni. Unsur kebaruan yang menyertai suatu karya amatlah penting untuk membangun citra dan eksistensi suatu nilai hadir di tengah-tengah kebudayaan ${ }^{[3]}$.

Tinjauan karya sebagai pembanding dari karya terdahulu yang memiliki hubungan dengan karya pengkarya, karya yang akan diciptakan yaitu:

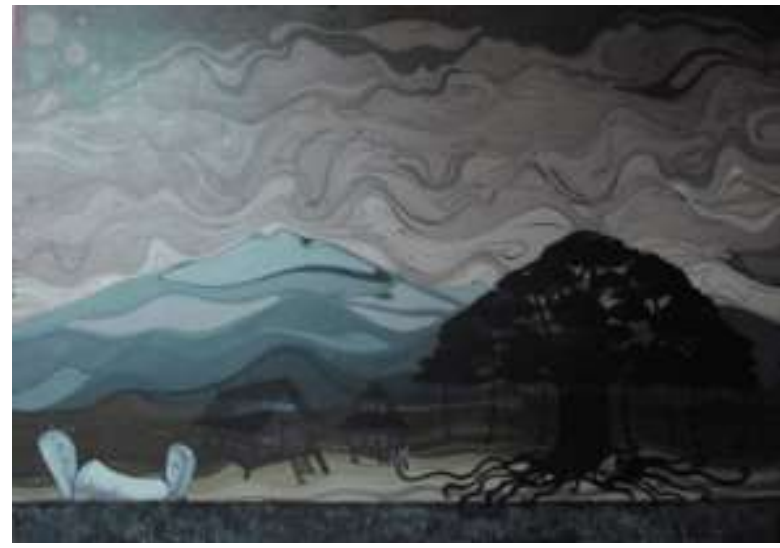

Gambar 1. Alim Budi Wijaya (2014), "RIP (Rain In Peace) 2014", 120 x 170. Mix Media di Atas Kanvas (Sumber: Budiwijaya, 2014).

Gambar 1. Merupakan karya seni lukis dengan gaya dekoratif, menggambarkan bahwa pengkarya merasa prihatin terhadap tidak ada produksi baru dari Jangkoi. Pengkarya mentransformasikan "Jangkoi" kedalam bentuk makam pada sudut kiri bawah serta garis-garis lengkung menyimbolkan rasa hanyut dalam duka. Di ujung kanan bawah terlihat pohon beringin yang pengkarya simbolkan sebagai rasa duka pengkarya terhadap ketidak pedulian pemerintah untuk benda budaya bersejarah ini.Sedangkan ujung kanan bawah terlihat sebuah kuburan/ makam pengkarya menyimbolkan hujan kedamaian (kepedulian pengkarya terhadap Jangkoi). Kesamaan pada karya 


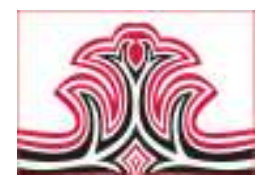

diatas ialah pada Jangkoi yang menjadi tema karya namun secara garapan maupun teknik berbeda.

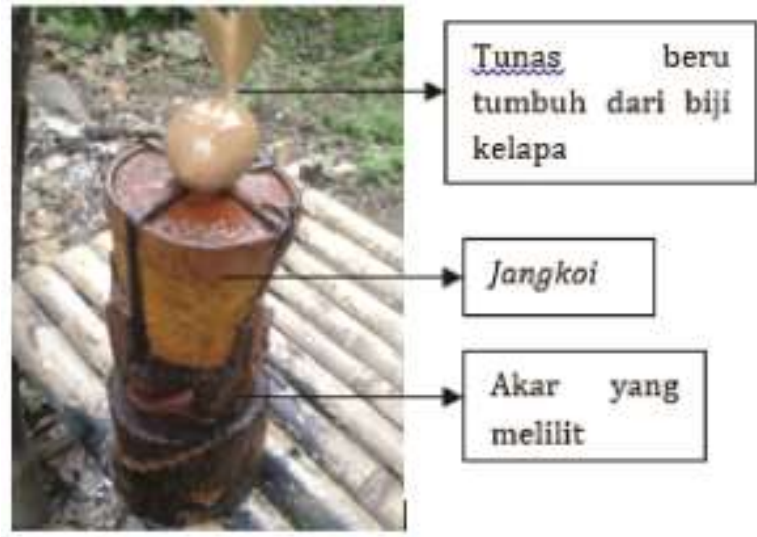

Gambar 2. Antoni Juanda (2013), "Demi Sang Buah Hati”, 50 x 15 Cm. Kayu Surian.

(Sumber: Antoni, 2013).

Karya ini merupakan karya kriya kayu yang menampilkan tiga objek yang berbeda objek pertama yaitu Jangkoi, objek yang kedua yaitu akar yang melilit atau membelenggu Jangkoi, objek yang ketiga yaitu biji kelapa yang baru tumbuh. Kesamaan karya diatas dengan karya yang akan digarap yaitu masih mengacu pada tema namun juga secara teknik dan garapan yang menjadi pembeda.

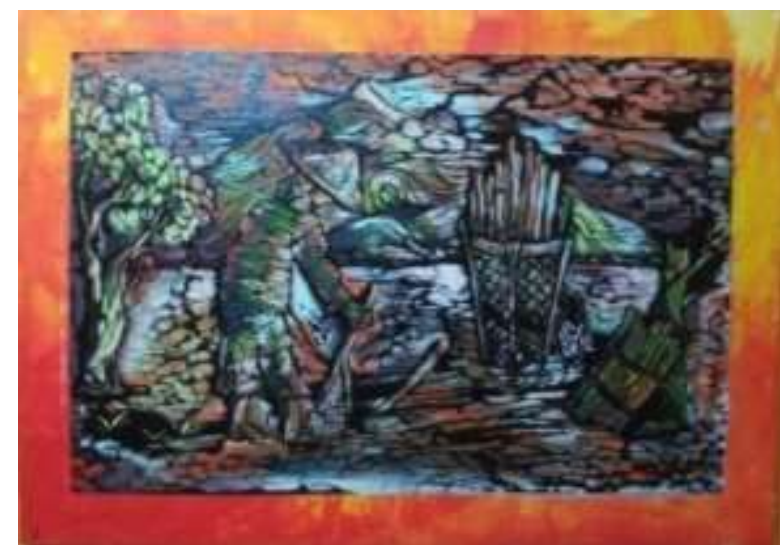

Gambar 3. Repi Justian 2018 "Nalok Kayau (Mencari Kayu)" Mix Medium, Reliefprint and Handcolouring on Canvas 140 x 100 Cm, 2018.

(Sumber: Repi Justian, 2018).

Karya yang berjudul "Nalok Kayau (Mencari Kayu)" diatas yang berukuran $140 \mathrm{~cm}$ x $100 \mathrm{~cm}$ adalah karya seni grafis dengan teknik Mix Medium memberi multi tafsir atau multi pemaknaan tentang eksistensi Jangkoi dulu dan hari ini dengan sentuhan representasional yaitu menghadirkan kembali bentuk Jangkoi kedalam karya serta hadirnya ikon-ikon daerah Kerinci sebagai penguat reinterpretasi karya. Kesamaan karya di atas dengan karya yang akan digarap yaitu pada tema dan proses garapan dan yang membedakan ialah pada bentuk dan pemaknaan yang nantinya akan lebih maksimal.
Gorga : Jurnal Seni Rupa

Volume 09 Nomor 02 Juli-Desember 2020 p-ISSN: 2301-5942 | e-ISSN: 2580-2380

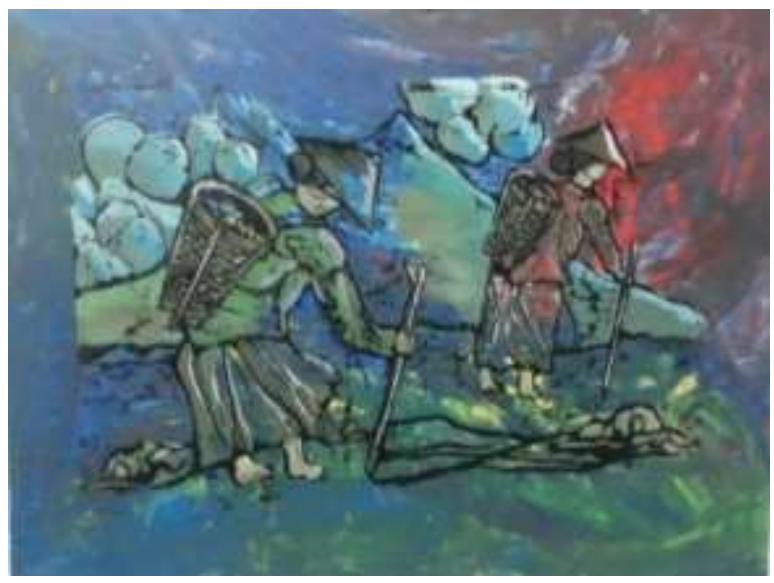

Gambar 4. Repi Justian "Bayalea Samamao (Berjalan Bersama)" Mix Medium, Reliefprint and Handcolouring on Canvas 110 x 80 Cm, 2018

(Sumber: Repi Justian, 2018).

Karya yang berjudul "Bayalea Samamao" diatas yang berukuran $110 \mathrm{~cm}$ x $80 \mathrm{~cm}$ merupakan karya Mix Medium pemaknaan tentang eksistensi Jangkoi dengan sentuhan revitalisasi yaitu menghadirkan kembali bentuk Jangkoi kedalam karya dengan ikon-ikon daerah kerinci sebagai penguat reinterpretasi karya. Wanita tua memberi pemaknaan tentang perjuangan pada saat menjadi mayoritas dipergunakannya Jangkoi.

\section{Konsep Penciptaan}

Penggarapan karya diangkat dari Jangkoi yang ada di daerah kerinci. Jangkoi merupakan benda budaya yang memiliki fungsi sebagai alat untuk membawa hasil perkebunan oleh masyarakat Kerinci. Perkembangan teknologi yang semakin maju mengakibatkan Jangkoi tidak lagi digunakan, sehingga pengkarya ingin mengangkat Jangkoi sebagai ide penciptaan karya seni karena benda ini termasuk hasil karya tradisi fungsional yang harus dilestarikan.

\section{1). Konsep Seni}

Seni merupakan suatu wujud yang terindera. Karya seni merupakan sebuah benda atau artefak yang dapat diihat, didengar atau dilihat dan sekaligus didengar (visual, audio dan audio-visual), seperti lukisan, musik dan teater ${ }^{[4]}$. Sudjojono berpendapat bahwa seni adalah jiwa yang nampak, sebagai motornya seni modern Indonesia, apa yang dikatakan oleh Sudjojono bahwa seni adalah jiwa ketok atau bahwa seni adalah jiwa yang menyembul ke luar.

\section{2). Konsep Visual (Tata Susun)}

Penciptaan karya seni grafis ini sejalan dengan prinsip estetika Monroe Breadsley di dalam Dharsono, yakni: 


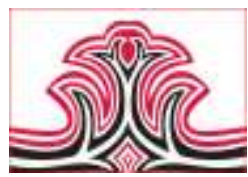

Kesatuan (unity) ini berarti bahwa benda estetis ini tersusun secara baik atau sempurna bentuknya, kerumitan (Complexity) benda estetis atau karya seni bersangkutan tidak sederhana sekali, malainkan kaya akan ini maupun unsur-unsur yang saling berlawanan ataupun mengandung perbedaan-perbedaan yang halus, dan kesungguhan (intensity) suatu benda yang estetis yang baik harus mempunyai suatu kualita tertentu yang menonjol dan bukan sekedar sesuatu yang kosong. Tak menjadi soal kualitas apa yang dikandungannya (minsalnya suasana suram atau gembira, sifat lembut atau kasar), asalkan merupakan sesuatu yang intensif atau sungguh-sungguh ${ }^{[5]}$.

\section{3). Konsep Garap}

Lahirnya karya mengungkapkan perasaan yang ada pada karya tersebut yang menghadirkaan seperti mimpi, kebebasan imajinasi tertuangkan ke dalam karya sehingga perasaan sesungguhnya bisa masyarakat lebih mudah memahami tentang isi dari karya nantinya. Seperti yang telah dijelaskan Dharsono didalam bukunya, yaitu:

"Surrealime adalah otomatis psikis murni, dengan proses pemikiran yang sebenarnya untuk diekspresikan secara verbal, tertulis ataupun cara lain. Surrealisme bersandar pada keyakinan reaitas yang superior dari kebebasan asosiasi, keserbabisaan mimpi, pemikiran kita yang otomatis tanpa kontrol dari kesadaran ${ }^{[5]}$."

Hadirnya karya-karya nantinya semoga dapat menjadi pemicu masyarakat Kerinci dapat melakukan pelestarian yang lebih baik nantinya serta keberadaannya selalu dihargai untuk menjadi artefak budaya. Keberhargaan segala sesuatu dalam masyarakat terletak pada kehidupan sosial dan kebudayaan, salah satunya Jangkoi sejak dahulu telah memberikan manfaat untuk masyarakat.

\section{METODE PENELITIAN}

\section{Observasi}

Observasi yang dilakukan adalah pengamatan terhadap fungsi Jangkoi pada masyarakat Kerinci. Observasi dilakukan untuk melihat perkembangan Jangkoi sebagai benda fungsional dan benda budaya yang dimiliki masyarakat Kerinci.

\section{Wawancara}

Wawancara dilakukan untuk mendapatkan informasi yang tepat tentang Jangkoi dari narasumber atau budayawan, didapatkan data-data yang valid. Wawancara dilakukan dengan beberapa tokoh budayawan Kerinci antara lain; Iskandar Zakaria dan Nazirman. Hasil wawancara dapat menguatkan pengkarya dalam proses menciptakan karya seni grafis.
Gorga : Jurnal Seni Rupa

Volume 09 Nomor 02 Juli-Desember 2020

p-ISSN: 2301-5942 | e-ISSN: 2580-2380

\section{Dokumentasi}

Dokumentasi digunakan untuk pencarian dan pengumpulan data atau foto tentang Jangkoi saat ini, gunanya untuk mempermudah pengkarya mendapatkan objek-objek yang akan dihadirkan dalam karya. Hal ini juga bisa dilakukan oleh pengkarya dengan penguasaan bentuk yang baik dalam membuat karya.

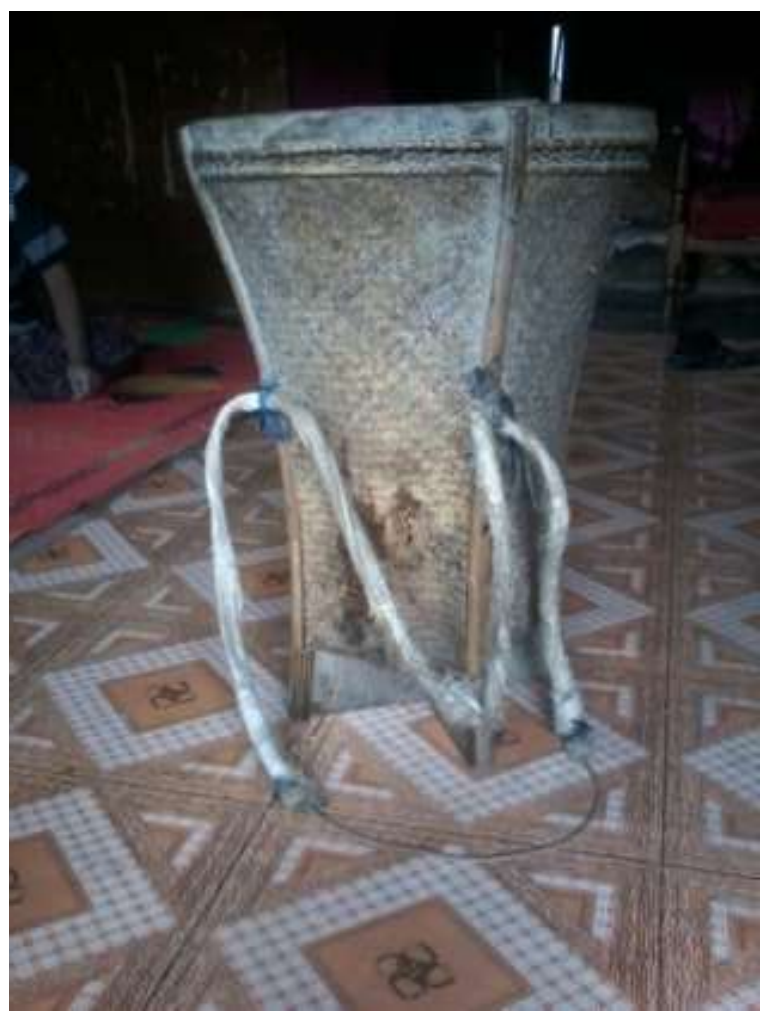

Gambar 5. Jangkoi (Sumber: Repi Justian, 2018)

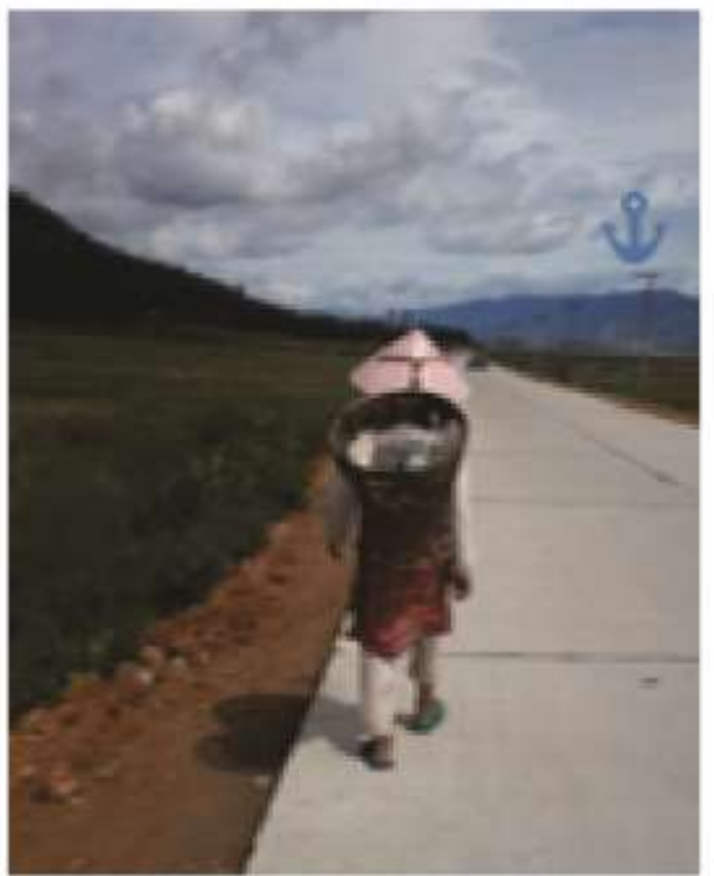




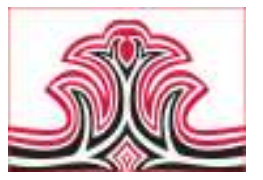

Gambar 6. Jangkoi

(Sumber: Repi Justian, 2018).

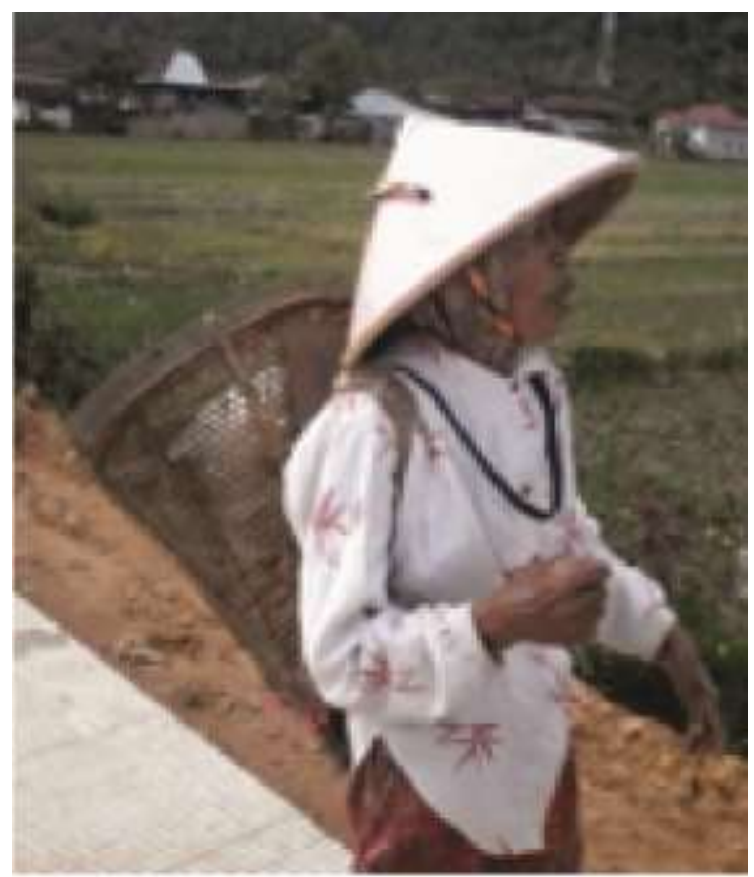

Gambar 7. Jangkoi

(Sumber: Tono Demitra, 2018).

Pada 2 dokumentasi di atas merupakan salah satu masyarakat yang masih menggunakan Jangkoi, lokasi Semerap.

\section{Eksperimen}

Eksperimen merupakan langkah kegiatan yang dilakukan seniman atau desainer dalam langkah proses penciptaan ${ }^{\{6\}}$. Eksperimen akan menghasilkan kualitas dalam memilih beberapa alternatif untuk mewujudkan sebuah karya sehingga seniman nantinta akan dipermudah mengekspresikan atau mengungkapkan perasaan secara individu.

\section{1). Teknik}

Dalam proses pembuatan karya digunakan teknik relief print dan Handcolouring atau lebih tepatnya Mix Medium serta menggunakan Monoprint.

\section{(1). Cetak Tinggi (Relief Print)}

Teknik cetak tinggi atau relief print adalah salah satu dari beberapa macam teknik print atau cetak yang memiliki acuan permukaan yang timbul atau meninggi, dimana berfungsi sebagai penghantar tinta, baik monokrom maupun polikrom.

\section{(2). Handcolouring}

Handcolouring Merupakan cara untuk pewarnaan karya yang dilakukan dengan kuas serta cat warna dengan pengaplikasian langsung ke medium kanvas.
Gorga : Jurnal Seni Rupa

Volume 09 Nomor 02 Juli-Desember 2020

p-ISSN: 2301-5942 | e-ISSN: 2580-2380

(3). Penggabungan Teknik Relief Print dan Handcolouring atau Mix Medium

Dalam proses pembuatan karya menggunakan penggabungan dua teknik yaitu relief print dan handcolouring dimana teknik relief print digunakan untuk mendapatkan kontur hitam pada objek karya dengan cara mencukil hardboard lalu bagian yang tidak kena cukil menjadi kontur hitam sedangkan Handcolouring digunakan dalam proses pewarnaan pada karya dengan cara kuas serta cat teraplikasi langsung kemedium kanvas.

\section{2). Bahan}

Adapun bahan yang digunakan dalam pembuatan karya seni grafis ini antara lain: Hardboard, kanvas, tinta cetak, spanram,cat dasar, dan cat akrilik.

\section{3). Alat}

Adapun alat yang digunakan dalam pembuatan karya seni grafis yaitu: pisau cukil, roler, penggosok/baren, kuas, gun tacker, pensil, spidol, sendok dempul, batu asah dan triplek.

\section{Perenungan}

Perenungan merupakan penggambaran batin sang seniman dalam mencari simbol (metafor). Perenungan dilakukan untuk mencari serta menemukan simbolsimbol (bahasa metefor) yang akan menjadi ikon dalam proses kreatif artistik dalam penciptaan karya seni $^{[7]}$.

\section{Pembentukan}

\section{1). Proses Pembuatan Sketsa}

Proses pembuatan sketsa adalah proses pengkarya mengeksplorasi - bentuk bentuk dan penyusunanpenyusunan komposisi gambaran karya yang dibuat padan kertas HVS, yang merupakan gambaran awal terbentuknya karya nantinya dan dibuat agar gambaran karya tersebut terlihat secara global dan menyeluruh.

\section{2). Proses Pemindahan Sketsa}

Proses pemindahan sketsa alternatif adalah proses pemindahan sketsa yang awalnya dibuat dikertas HVS dan dipindahkan ke (hardboard/mdf) dengan cara membuat langsung ke (hardboard/mdf) menggunakan skala. Proses menggunakan skala pada tiap-tiap karya akan berbeda tergantung sketsa yang dibuat dan posisi karya yang dengan posisi potrait atau lanscape.

\section{3). Proses Pemasangan Kain Kanvas ke Spanram}

Proses pemasangan kain kanvas ke spanram adalah proses pembentangan kain kanvas pada spanram. Pemasangan kain kanvas dilakukan dengan cara 
meletakkannya di atas lantai, dimana posisi kanvas terletak pada bagian bawah dan spanram di atas kanvas. Proses pemasangan ini dilakukan dengan cara manual, yaitu dimana kanvas ditegangkan dengan menggunakan kedua tangan. Kanvas disemat dengan menggunakan gun tacker untuk mengunci kanvas yang telah diregangkan pada spanram.

\section{4). Proses Mendasari Kain Kanvas}

Proses mendasari kain kanvas adalah proses dimana kain kanvas akan dilapisi dengan cat pelapis. Proses mendasari kain kanvas ini dilakukan tiga sampai empat kali sampai kain kanvas akan terlihat sedikit licin, jika licin akan mempermudah dalam proses pencetakan kontur nantinya.

\section{5). Proses Pencukilan}

Proses pencukilan ini dilakukan dengan menghilangkan bagian yang tidak di ingin kan pada master cetakan, atau pada karya yang tidak untuk menjadi bagian dari cetakan kontur karya yang sesuai dengan sketsa yang dibutuhkan.

\section{6). Proses Kontur Hitam Putih}

Proses pencetakan kontur hitam merupakan pemindahan gambaran dari master cetakan yang awalnya telah tercukil terlebih dahulu. Kemudian dicetak pada kain kanvas yang telah diregangkan dan didasari dengan cat perlapis.

\section{7). Pewarnaan Karya}

proses pewarnaan karya adalah dimana proses ini merupakan proses pemberian warna pada medium kanvas yang telah diberi patokan kontur hitam putih terlebih dahulu pada tahap sebelumnya. proses ini dilakukan dengan menggunakan pewarnaan handcolouring atau pewarnaan langsung dengan menggunakan kuas dan cat langsung kemedium kanvas dan dilakukan dengan teliti sesuai patokan dan warna tertentu yang dibutuhkan.

\section{8). Pencetakan Kontur Akhir}

proses ini merupakan dimana pemberian kontur hitam dengan menggunakan tinta cetak yang sedikit tebak pada bagian master cetakan dan dicetak pada kanvas yang telah diberi warna dengan pewarnaan handcolouring. Caranya mirip dengan proses pencetakan kontus hitam putih pada tahan yang sebelumnya dan dilakukan dengan teliti dan sesuain dengan letak master cetakan yang dilakukan pada proses pencetakan kontur hitam putih, tujuannya agar terlihat pas, sesuai dan tidak bergeser.

\section{9). Finishing}

Finishing adalah proses akhir dari pembuatan karya dan dalm proses ini dilakukan proses pengecatan keempat sisi dari karya supaya nantinya karya tersebut akan terlihat rapi dan bersih. Dan pada proses ini merupakan proses yang terakhir kemudian karya ini siap untuk mengikuti pameran.

\section{HASIL DAN PEMBAHASAN}

\section{Hasil}

Di Kabupaten Kerinci terdapat keanekaragaman budaya yang menghiasi masyarakatnya dan peninggalan-peninggalan yang menarik untuk dikaji, namun pengkarya tertarik pada benda budaya Jangkoi yang ada di Kerinci serta bagaimana keberadaannya saat ini yang telah terkesampingkan oleh perkembangan zaman. Jangkoi merupakan benda budaya yang masih hidup dan berkembang pada masyarakat Kerinci dari tempo dulu.

Karya seni grafis yang akan dibuat nantinya dengan menggunakan konsep Surrealisme. Dikatakan oleh Breton, bahwa Surrealisme adalah otomatis psikis yang murni, dengan proses pemikiran yang sebenarnya untuk diekspresikan secara verbal, tertulis ataupun cara lain. Surrealisme bersandar pada keyakinan realitas yang superior dari kebebasan asosiasi,keserbabisaan mimpi, pemikiran kita yang otomatis tanpa kontrol dari kesadaran. Kreatifitas kaum Surrealis berusaha membebaskan dari kontrol kesadaran, menghendaki sebebas orang yang sedang bermimpi. (Dharsono, 2017). Surrealisme membuat kebebasan dari karya yang lahir nantinya, kebebasan berekspresi, perasaan personal yang menyentuh kalbu pengkarya menanggapi apa yang terjadi pada benda budaya Jangkoi saat ini.

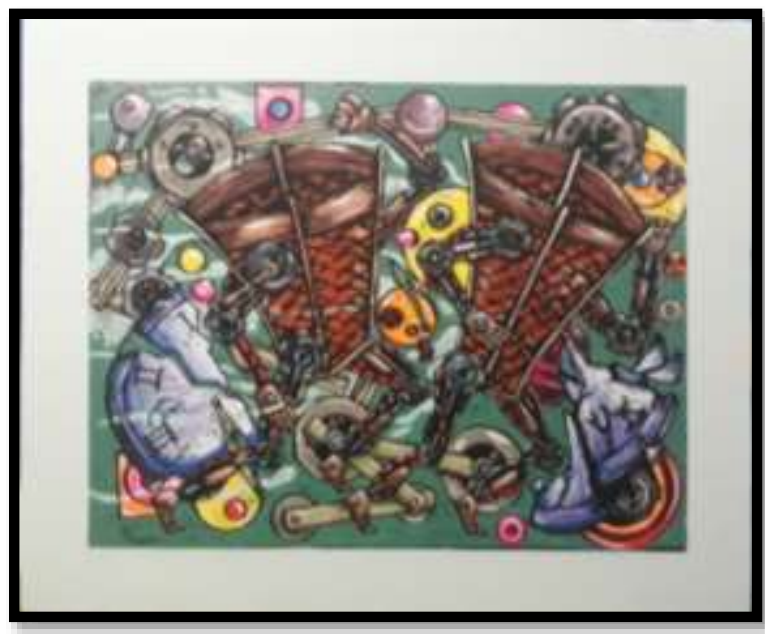

Gambar 8. "Kaehlah (Cepatlah)" Mix Medium, Reliefprint and Handcolouring on Canvas 110 x $90 \mathrm{Cm}$. (Sumber: Repi Justian, 2020) 
2. Pembahasan

\section{1). Deskripsi}

Karya 5 yang berjudul Kaehlah (Cepatlah) dibuat pada tahun 2020 menggunakan media campuran atau mix medium yaitu media seni grafis dan media seni lukis, yang mana media seni grafis menggunakan teknik cetak tinggi (Reliefprint) sebagai pembentuk kontur cetak serta media seni lukis sebagai cara pewarnaan atau pewarnaan manual (handcoluring). Karya menggunakan cat akrilik dan tinta minyak diatas kanvas yang berukuran 110 x $90 \mathrm{~cm}$.

Secara keseluruhan karya menerapkan perpaduan tingkatan warna panas dan warna dingin. Pada bagian background menggunakan warna biru muda. Objek utama karya terlihat dua buah Jangkoi berwarna coklat dengan gradasi warna coklat tua ke coklat muda dengan menggunakan sepasang tangan dan kaki robot dengan perpaduan warna coklat muda, merah abu-abu dan biru. Sisi kiri dan kanan bawah karya terdapat objek jam dinding yang pecah dengan perpaduan tingkatan warna biru, violet, dan violet muda. Objekobjek background karya sebagai pendukung dengan lingkaran berbagai ukuran dan lingkaran tidak sempurna, bentuk-bentuk persegi dengan warna-warna seperti kuning, jingga violet serta merah muda, bagian bawah karya terlihat seperti roda besi yang tersambung oleh batang besi dengan warna abu-abu bergradasi tua ke muda, bagian atas terlihat seperti gir yang tersambung oleh batang besi dengan warna abuabu bergradasi tua ke muda.

\section{2). Analisis}

Karya yang berjudul "Kaehlah (Cepatlah) menerapkan tiga aspek estetika Monroe Brandsley yakni unity, complexity dan intensity. Berikut ini adalah penguraian struktur karya:

\section{(1). Unity}

\section{a. Unsur Rupa}

Bangun (Shape) yang ada pada karya adalah bangun yang menyerupai wujud alam (figur), bidang pada karya membentuk lingkaran yang sempurna namun tertutup oleh objek utama dan lingkatang dengan perpeduan dengan bentuk persegi yang tak sempurna membentuk gir-gir. Garis lengkung yang berpadu dengan garis lurus tak beraturan membentuk jam dinding yang rusak pada sisi kiri dan kanan bawah karya. Garis-garis lurus membentang membentuk persegi panjang dan memberi figur besi yang. Objek utama yang begitu menonjol tengah-tengah karya yang berbentuk Jangkoi terlihat berpadu dengan garis lengkung dan lurus membentuk lengan dan kaki robot serta objek-objek pada background memberi sebegai pendukung suasana robotik karya.
Warna yang dihadirkan adalah tingkatan-tingkatan warna panas dan dingin, warna panas yakni jingga, merah dan merah muda, kemudian warna dingin ialah biru muda, warna violet coklat, coklat muda dan abuabu. Warna biru muda pada background karya yang terdapat pada sekeliling karya. Pada setiap objek pendukung pada sisi belakan objek utama dengan warna panas dan dingin. Komposisi warna yang ada pada karya memberi kesan semangat, pantang menyerah.

\section{b. Dasar Penyusunan}

Paduan harmoni atau selaras dalam karya terlihat pada bagian warna dan garis. Warna yang selaras pada perpaduan backgound dan objek karya. Keselarasan warna panas yakni biru muda dan pada objek berwarna coklat tua dan coklat muda pada Jangkoi, namun perpaduan warna panas dan dingin memberikan keselarasan yang unik. Garis-garis pada karya membentuk figur benda-benda mekanik yang lebih dominan pada bagian background memberikan kesan irama dan repetisi.

\section{c. Hukum Penyusunan}

Penerapan hukum keseimbangan dalam karya keseimbangan formal. Keseimbangan formal terlihat dari bagian-bagian pada karya yang memiliki proporsi yang sama atas, bawah, kiri dan kanan. Dalam karya ini terlihat center of interest terletak pada tengah karya. Kesederhanan dalam karya ini sangat jelas terlihat, hal ini diamati dari figur dua buah Jangkoi. Dalam karya ini terlihat sangat jelas aksentuasi pada perbedaan warna background dan objek, bias warna antara objek yang tak kalah oleh warna background dan objek terlihat menonjol dari background.

\section{(2). Complexity}

Complexity atau kerumitan jelas terlihat pada karya yaitu pada kerumitan pembentukan cukilan anyaman objek utama, yakni teknik seni grafis. Dalam seni grafis, garis yang terbentuk bukanlah garis yang dilukis atau digores menggunakan kuas melainkan dicetak. Proses pembuatan yang dilakukan melalui tahap yang sangat rumit.

\section{(3). Intensity}

Secara intensity dapat dilihat pada kesungguhan dalam menggarap karya. Tidak ada bagian-bagian pada karya yang tidak gergarap dengan baik. Capaian keseluruhan karya dapat dilakatakan sangat baik, sebab tidak ditemukan semacam kesalahan dalam penggarapan seperti bekas geser ketika proses pencetakan karya, bercak tinta yang menyebar dan lain-lain. Kesungguhan secara menyeluruh dalam penggarapan 


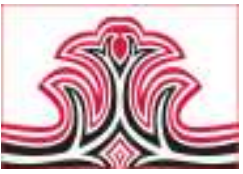

jelas terlihat, dimana unsur-unsur yang dihadirkan sangat terukur. Ketelitian dalam menentukan bagianbagianyang digarap yaitu komposisi bidang, garis dan warna sangat tertata dengan baik.

\section{c. Interpretasi}

Karya menggambarkan situasi keadaan Jangkoi yang harus dilestariakan mengikuti perkembangan zaman, perkembangan zaman yang kita ketahui saat ini sangat luar biasa, bila kita termenung dan melihat-lihat saja maka kita akan tertinggal, begitu pula layaknya Jangkoi diperlakukan mengikuti perkembangan zaman, mengikuti inovasi yang cerdas terhadap Jangkoi tanpa mengubah bentuk utama. Suasan karya memberi kesan semangat yang menggebu bahwa kita tak boleh tertinggal oleh perkembangan zaman.

\section{KESIMPULA DAN SARAN}

\section{Kesimpulan}

Di Kabupaten Kerinci terdapat keaneka ragaman budaya yang menghiasi masyarakatnya dan peninggalan-peninggalan yang menarik untuk dikaji, namun pengkarya tertarik pada benda budaya Jangkoi yang ada di Kerinci serta bagaimana keberadaannya saat ini yang telah terkesampingkan oleh perkembangan zaman. Jangkoi merupakan benda budaya yang masih hidup dan berkembang pada masyarakat Kerinci dari tempo dulu. "Jangkoi" yaitu alat untuk mengangkut padi saat sudah dituai. Dilihat dari bentuk, maka benda ini mirip dengan keranjang besar yang terbuat dari rotan. Maka dari itu ditemukan rumusan masalah yakni "bagaimana menciptakan Karya seni Grafis Jangkoi sebagai Inspirasi dalam Karya Seni Grafis sebagai karya seni grafis surrealisme dengan Jangkoi ide gagasan.

\section{Saran}

Selama proses penciptaan karya ini banyak hal yang masih belum terjajah dan masih dapat dijadikan sebagai bahan pengembangan, baik itu berbentuk ide garapan, konsep, maupun eksplorasi teknis yang memunculkan kebaruan-kebaruan dalam mengolah karya seni grafis. Teknik-teknik pada seni grafis pada dasarnya depar dikombinasikan secara bersamaan ataupun dengan medium seni rupa dua demensi lainnya yang dapat dilakuakn secara bersamaan. Hal ini terbukti atas lahirnya karya-karya yang telah melalui tahapan tersebut. Hal ini sangat bermanfaat dan dapat dijadikan bahan kajian ilmiah untuk proses penciptaan karya-karya seni grafis selanjutnya.
Gorga : Jurnal Seni Rupa

Volume 09 Nomor 02 Juli-Desember 2020

p-ISSN: 2301-5942 | e-ISSN: 2580-2380

\section{DAFTAR RUJUKAN}

Sachari, Agus. (2002). Estetika, Makna, Simbol dan Daya. Bandung: Penerbit ITB.

Sony Kartika, Dharsono. (2016). Kreasi Artistik. Jaten Karanganyar: Citra Sain

Sony Kartika, Dharsono. (2004). Kreasi Artistik: Jaten Karanganyar: Citra Sain.

Sony Kartika, Dharsono. (2004). Pengantar Estetika. Bandung: Penerbit Rekayasa Sains.

Sumarjo, Jakob. (2000). Filsafat Seni. Bandung: Penerbit ITB.

Wawancara Iskandar Dzakaria, Budayawan Kerinci, 11 November 2017. 